\title{
Diet and irradiation effects on the bacterial community composition and structure in the gut of domesticated teneral and mature Queensland fruit fly, Bactrocera tryoni (Diptera: Tephritidae)
}

Deane N. Woruba ${ }^{1,2,3^{*}}$, Jennifer L. Morrow ${ }^{2}$, Olivia L. Reynolds ${ }^{1,3,4,5}$, Toni A. Chapman ${ }^{1,3}$, Damian P. Collins ${ }^{6}$ and Markus Riegler $2^{*}$

\begin{abstract}
Background: Mass-rearing, domestication and gamma irradiation of tephritid fruit flies used in sterile insect technique (SIT) programmes can negatively impact fly quality and performance. Symbiotic bacteria supplied as probiotics to mass-reared fruit flies may help to overcome some of these issues. However, the effects of tephritid ontogeny, sex, diet and irradiation on their microbiota are not well known.

Results: We have used next-generation sequencing to characterise the bacterial community composition and structure within Queensland fruit fly, Bactrocera tryoni (Froggatt), by generating 165 rRNA gene amplicon libraries derived from the guts of 58 individual teneral and mature, female and male, sterile and fertile adult flies reared on artificial larval diets in a laboratory or mass-rearing environment, and fed either a full adult diet (i.e. sugar and yeast hydrolysate) or a sugar only adult diet. Overall, the amplicon sequence read volume in tenerals was low and smaller than in mature adult flies. Operational taxonomic units (OTUs), belonging to the families Enterobacteriaceae (8 OTUs) and Acetobacteraceae (1 OTU) were most prevalent. Enterobacteriaceae dominated laboratory-reared tenerals from a colony fed a carrot-based larval diet, while Acetobacteraceae dominated mass-reared tenerals from a production facility colony fed a lucerne chaff based larval diet. As adult flies matured, Enterobacteriaceae became dominant irrespective of larval origin. The inclusion of yeast in the adult diet strengthened this shift away from Acetobacteraceae towards Enterobacteriaceae. Interestingly, irradiation increased 165 rRNA gene sequence read volume.

Conclusions: Our findings suggest that bacterial populations in fruit flies experience significant bottlenecks during metamorphosis. Gut bacteria in teneral flies were less abundant and less diverse, and impacted by colony origin. In contrast, mature adult flies had selectively increased abundances for some gut bacteria, or acquired these bacteria from the adult diet and environment. Furthermore, irradiation augmented bacterial abundance in mature flies. This implies that either some gut bacteria were compensating for damage caused by irradiation or irradiated flies had lost their ability to regulate bacterial load. Our findings suggest that the adult stage prior to sexual maturity may be ideal to target for probiotic manipulation of fly microbiota to increase fly performance in SIT programmes.
\end{abstract}

Keywords: Sterile insect technique, microbiome, 16S rRNA gene, Enterobacteriaceae, Acetobacteraceae, Asaia sp.

\footnotetext{
*Correspondence: dworuba@gmail.com; m.riegler@westernsydney.edu.au

'Plant Biosecurity Cooperative Research Centre, LPO, Box 5012, Bruce, ACT

2617, Australia

${ }^{2}$ Hawkesbury Institute for the Environment, Western Sydney University,

Locked Bag 1797, Penrith, NSW 2751, Australia

Full list of author information is available at the end of the article
}

(c) The Author(s). 2019 Open Access This article is distributed under the terms of the Creative Commons Attribution 4.0 International License (http://creativecommons.org/licenses/by/4.0/), which permits unrestricted use, distribution, and reproduction in any medium, provided you give appropriate credit to the original author(s) and the source, provide a link to the Creative Commons license, and indicate if changes were made. The Creative Commons Public Domain Dedication waiver (http://creativecommons.org/publicdomain/zero/1.0/) applies to the data made available in this article, unless otherwise stated. 


\section{Background}

In the quest to understand the association between bacteria and their insect hosts, one of the first associations studied was a tephritid fruit fly pest, the olive fly, Bactrocera oleae (Rossi) (Diptera: Tephritidae) and its gut microbiota [1]. Over the past decade, there has been increasing interest in symbiosis of bacteria with tephritids, particularly the potential manipulation of this association for pest management $[2,3]$. One such prospect involves the use, or manipulation of microbial symbionts as part of the sterile insect technique (SIT) [4].

SIT involves mass rearing (leading to domestication [5]) and the release of irradiated (sterile) individuals of the target pest species into wild pest populations in the field [6]. The success of SIT relies upon sterile males locating and successfully copulating with field females, resulting in embryonic mortality and a decline of the pest population. However, released sterile tephritid males are less competitive than their field male counterparts due to the processes of mass-rearing and exposure to ionizing radiation [7].

Tephritids are holometabolous insects with different nutritional environments and requirements during their developmental stages [8]. To attain sexual maturity and achieve good sexual performance certain nutrients are relevant, particularly at the adult stage [9]. For example, yeast, as a protein source, is known to affect adult male and female tephritid fitness and performance differently during the development [10]. Fruit flies harbour symbiotic bacteria in their gut and research suggests that they are involved in the fly's nutritional status. As environmental factors are known to shape the composition and structure of bacterial communities in tephritids [11], tephritid development may also impact their gut microbiome and therefore condition how resources are used. Furthermore, diets and exposure to irradiation are known to affect the performance of mass-reared adult tephritids [12]. Although it is known that exposure to irradiation damages the tephritid gut [13], little is known about how this affects the gut microbiome. In this sense, a supplementation of symbiotic bacteria to mass-reared irradiated tephritids is expected to improve their performance $[14,15]$. Therefore, an improved understanding of the gut bacterial communities, and how they are impacted by insect development and environmental factors (such as diets and irradiation) may lead to the identification of beneficial symbiotic gut bacteria and how these may be promoted in flies, e.g. through probiotic supplementation.

In Australia, SIT is used in an integrated approach to control the serious horticultural pest, Queensland fruit fly, Bactrocera tryoni (Froggatt) (Diptera: Tephritidae) $[16,17]$. The aim of the present study was to investigate the bacterial community composition and structure within the gut of domesticated populations of B. tryoni flies and determine the effects of colony origin, adult developmental stage, sex, adult diets, rearing environment, and exposure to gamma irradiation on gut microbiota. We hypothesised that diet and irradiation affect the gut microbiome. We used 16S rRNA gene amplicon nextgeneration sequencing (NGS) to characterise the gut bacterial communities of teneral (immature) and mature adult B. tryoni, irradiated and unirradiated, maintained on varying adult diets in order to understand the bacterial population dynamics across adult development and to identify an optimal time point for adult probiotic supplementation to enhance adult fruit fly performance for SIT.

\section{Methods}

Treatment of teneral and mature adults

The flies for the characterisation of the bacterial communities were sampled from two colonies of $B$. tryoni in late January 2015. These two colonies were originally sourced from two different field-collected lines and then independently maintained at two rearing facilities that used larval diets comprising different bulking agents. The first B. tryoni colony was from the Fruit Fly Production Facility (FFPF) of the Elizabeth Macarthur Agricultural Institute (EMAI), NSW Department of Primary Industries (NSW DPI) in Menangle, New South Wales (NSW). This colony was maintained for use in the Queensland fruit fly SIT program and was sourced from a line derived from $B$. tryoni infested fruits collected in the NSW Central Coast region in 2013 and established at the NSW DPI's Central Coast Primary Industries Centre (CCPIC), in Ourimbah, NSW. At the FFPF, mass-reared individuals (> 5 million/week; 5000 larvae per litre larval diet [personal communication S Balagawi]) of this 2 year-old colony were reared on standard fruit fly larval growth medium using lucerne chaff as the bulking agent, torula yeast, white cane sugar, water, citric acid, sodium benzoate and methyl paraben [18].

The second B. tryoni colony (BtGWS in [11]) was from the laboratory of the Hawkesbury Institute for the Environment (HIE), Western Sydney University, Richmond, NSW. This colony was maintained for research purposes and originated from a CCPIC line established from infested fruits collected in the field in the NSW Central West region in 2009. At HIE, laboratory-reared individuals (<500/cohort; approximately 3000 larvae per litre larval diet) of this 6 year-old laboratory colony [11] were reared on a larval diet consisting of dehydrated ground carrot as the bulking agent, torula yeast, water, hydrochloric acid and methyl paraben [19]. A key compositional difference between the two larval diets was the bulking agents (lucerne chaff versus ground carrot) that have minimal nutritional function, but rather provide a 
matrix to allow aeration and heat dissipation as the larvae feed and develop within the diet.

To cause sterility, half of the late-stage FFPF pupae were irradiated in a ${ }^{60} \mathrm{Co}$ in-ground gamma Technology Research Irradiator at the Australian Nuclear Science and Technology Organisation (ANSTO) in Lucas Heights, NSW, at the current recommended dose of 60-65 Gy and a dose rate of approximately $6 \mathrm{~Gy} \mathrm{~min}^{-1}$, while a second group of FFPF pupae were not irradiated and remained fertile. All pupae of the HIE cohort were fertile, i.e. unirradiated.

Adult flies were sampled from 18 experimental treatment groups based on adult developmental stage (teneral or mature adults), larval rearing environment (FFPF and HIE populations reared on different larval diets), irradiation status (irradiated or unirradiated), sex (male or female) and adult diet (sugar only, or full diet, i.e. 3:1 ratio of white sugar and yeast hydrolysate) (Table 1). In preparation for this, approximately 100 pupae from each of the experimental populations were set up in Petri dishes in separate $30 \mathrm{~cm} \times 30 \mathrm{~cm} \times 30 \mathrm{~cm}$ mesh covered cages (BugDorm, Taiwan) in a controlled glasshouse chamber at HIE at $25 \pm 3{ }^{\circ} \mathrm{C}, 65 \pm 15 \% \mathrm{RH}$ and a $10: 14 \mathrm{~h}$ light: dark photoperiod. The cages were monitored three times daily and flies sampled as teneral and mature adults. Tenerals were not provided with water or food and were sampled between 6 and $12 \mathrm{~h}$ post eclosion (tenerals less than $6 \mathrm{~h}$ old were not used as their digestive systems were soft and disintegrated when dissected). Captive adult $B$. tryoni reach maturity by 10 days $[19,20]$. Therefore, mature adults were sampled at 14 days, and were provided with water and either a full adult diet (sugar and yeast hydrolysate [3:1]) or a sugar only adult diet from eclosion. All adult diets were provided as $2 \%$ agar in a Petri dish [21]. The adult diets were replaced every second day.

\section{Gut dissection}

At least three samples of B. tryoni from each of the 18 experimental treatment groups (Table 1) were selected for gut dissections. Insects were placed in $250 \mathrm{~mL}$ specimen jars and, within $30 \mathrm{~min}$ of sampling, were anaesthetised with carbon dioxide for $1 \mathrm{~min}$. The insects were then surface sterilised by sequentially immersing for 1 min in each of $70 \%$ ethanol, sterile distilled water, $0.05 \%$ sodium hypochlorite and lastly sterile distilled water, before individuals were placed on a sterile concave glass slide that had been surface treated by wiping with $70 \%$ ethanol and $0.05 \%$ sodium hypochlorite. The glass slide was placed on top of ice in a plastic Petri dish, which was then viewed under a stereomicroscope. Two pipette drops of sterile phosphate-buffered saline (PBS) were placed on top of the insect before dissection with sterile

Table 1 Bactrocera tryoni experimental treatment groups

\begin{tabular}{|c|c|c|c|c|c|c|}
\hline Treatment group & Life stage & Colony origin & Larval diet bulking agent & Adult diet & Irradiation & Sex \\
\hline ELNIF & Teneral & EMAI-FFPF & Lucerne chaff & Nil & Irradiated & Female \\
\hline ELNIM & Teneral & EMAI-FFPF & Lucerne chaff & Nil & Irradiated & Male \\
\hline ELNUF & Teneral & EMAI-FFPF & Lucerne chaff & Nil & Unirradiated & Female \\
\hline ELNUM & Teneral & EMAI-FFPF & Lucerne chaff & Nil & Unirradiated & Male \\
\hline HCNUF & Teneral & HIE & Carrot & Nil & Unirradiated & Female \\
\hline HCNUM & Teneral & HIE & Carrot & Nil & Unirradiated & Male \\
\hline ELSIF & Mature & EMAI-FFPF & Lucerne chaff & Sugar only & Irradiated & Female \\
\hline ELYIF & Mature & EMAI-FFPF & Lucerne chaff & Full diet & Irradiated & Female \\
\hline ELSIM & Mature & EMAI-FFPF & Lucerne chaff & Sugar only & Irradiated & Male \\
\hline ELYIM & Mature & EMAI-FFPF & Lucerne chaff & Full diet & Irradiated & Male \\
\hline ELSUF & Mature & EMAI-FFPF & Lucerne chaff & Sugar only & Unirradiated & Female \\
\hline ELYUF & Mature & EMAI-FFPF & Lucerne chaff & Full diet & Unirradiated & Female \\
\hline ELSUM & Mature & EMAI-FFPF & Lucerne chaff & Sugar only & Unirradiated & Male \\
\hline ELYUM & Mature & EMAI-FFPF & Lucerne chaff & Full diet & Unirradiated & Male \\
\hline HCSUF & Mature & HIE & Carrot & Sugar only & Unirradiated & Female \\
\hline HCYUF & Mature & HIE & Carrot & Full diet & Unirradiated & Female \\
\hline HCSUM & Mature & HIE & Carrot & Sugar only & Unirradiated & Male \\
\hline HCYUM & Mature & HIE & Carrot & Full diet & Unirradiated & Male \\
\hline
\end{tabular}

Treatment group abbreviations represent treatments for individual samples with the first letter indicating the colony origin of either EMAI-FFPF (E) or HIE (H) from which the pupae were collected, the second letter indicating the larval diets of either carrot (C) or lucerne chaff (L), the third letter identifies the adult diet of either a full adult diet consisting of yeast hydrolysate and sugar $(3: 1)(Y)$, sugar only $(S)$ or nil $(N)$ as in the case of tenerals who were not fed, the fourth letter indicates if the pupae were irradiated (I) or unirradiated (U), the fifth letter denotes the sex, either male (M) or female (F). Adult diets were provided in a $1 \%$ agar matrix) 
forceps. The dissection involved firstly removing the wings, the legs and the exoskeleton after softening by immersion in PBS for $1 \mathrm{~min}$. The intact gut of the insects was then gently removed and placed in a clean 1.5 $\mathrm{mL}$ microcentrifuge tube and immediately transferred to a freezer $\left(-20^{\circ} \mathrm{C}\right)$ for a maximum of $1 \mathrm{~h}$. Afterwards, samples were stored at $-80^{\circ} \mathrm{C}$ until required.

\section{DNA extraction, library preparation and 16S rRNA gene amplicon sequencing}

DNA from each of 58 individual gut samples stored at $80^{\circ} \mathrm{C}$ was extracted using the QIAmp DNA mini kit (Qiagen), including RNase treatment, and eluted in $50 \mu \mathrm{L}$ nuclease-free water. DNA integrity was examined by gel electrophoresis. The DNA solutions were reduced to a volume between 15 and $20 \mu \mathrm{L}$ using a vacuum concentrator. DNA concentration and purity were assessed using Qubit 2.0 Fluorometry and Nanodrop spectrophotometry. Each genomic DNA sample was also PCR amplified using the eubacterial $16 \mathrm{~S}$ rRNA gene primers $63 \mathrm{~F}$ and $1227 \mathrm{R}$, and insect mitochondrial COI with primers Pat and Dick, as described in Morrow et al. [22], to ensure the DNA did not contain inhibitors that would interfere with amplification.

The DNA samples were then submitted for highthroughput sequencing at the HIE Next-Generation Sequencing Facility for 16S rRNA gene amplification of 7 ng DNA using primers 341F - 5' CCTACGGGNGGC WGCAG $3^{\prime}$ and 805R - 5' GACTACHVGGGTATCTAATCC 3 ', which span the variable V3 and V4 regions of the 16S rRNA gene producing a fragment of approximately $464 \mathrm{bp}$. Library preparation for 58 samples was performed with the Nextera XT kit, and sequencing of $2 \times 300$ bp paired ends was performed on a 384-multiplexed Illumina MiSeq run.

\section{Sequence analyses}

The data was analysed using the open-source bioinformatics pipeline QIIME [23]. The raw data of the 58 libraries received in fastq format were examined using FastQC v0.11.5 [24], which showed that trimming of at least $10 \mathrm{bp}$ from the 3' ends of $\mathrm{R} 1$ reads and $90 \mathrm{bp}$ from $\mathrm{R} 2$ reads would improve the quality of the merged sequences. Therefore, the reads were trimmed using the trimfq command of seqtk [25], removing the primer and the final 10 bp (-b 17 -e 10) from the forward (R1) reads, as well as the primer and final $90 \mathrm{bp}$ from the reverse (R2) reads (-b 21 -e 90). FLASH v1.2.11 [26] was used to join the trimmed, paired reads into single sequences with a minimum overlap of $10 \mathrm{bp}$.

The operational taxonomic units (OTUs) were assigned using the pick_open_reference_otus.py command which also removes singletons. Chimeric sequences were detected and removed using ChimeraSlayer [27].
After singleton and chimera removal, the number of sequence reads per library and alpha diversity indices were compared by pairwise ANOVA and plotted by using base $R$ commands in $\mathrm{R}$ [28]. Due to the significant difference in sequence read numbers obtained per library, following quality control, the data were split into two groups defined as teneral adults and mature adults, and then the sequences for each group were normalised to the lowest number of sequences found in each group using the command single_rarefaction.py. The rarefaction curves to assess coverage were created by the rarecurve command of the Vegan package [29] in R.

Beta diversity across the samples was analysed by the phylogenetic distance-based measurement, UniFrac and the abundance distance-based measurement, Bray-Curtis. The distance matrix values for unweighted UniFrac (presence and absence of taxa), weighted UniFrac (presence, absence and abundance of taxa) and Bray-Curtis (compositional dissimilarity based on counts) for the samples were calculated in QIIME. Then, the distance matrices were imported into $\mathrm{R}$ for statistical analysis of treatment effects and plotting of the principal component analysis (PCoA) and relative abundance. The ellipses in the PCoA plots were created using the ordiellipse command of the Vegan package and the heatmap plots were created using the levelplot command of the Lattice package [30] in R.

\section{Results}

\section{Sequence read analyses}

A total of 58 libraries from 19 teneral and 39 mature adult $B$. tryoni were high-throughput amplicon sequenced for approximately $460 \mathrm{bp}$ of their bacterial 16S rRNA gene with the primers $341 \mathrm{~F}$ and $805 \mathrm{R}$. This generated 2,453,686 raw sequence reads (Additional file 1 Table S1). After filtering, 1,088,483 (44.4\%) sequences remained and this large reduction in sequence read numbers was likely due to the reads being of low quality at the $3^{\prime}$ ends, which affects the number of read pairs that are merged into a complete sequence fragment, both by reducing the amount of overlap found in reads producing a larger merged sequence (i.e. $\sim 426 \mathrm{bp}$ ), or by having too much overlap in smaller sized sequences (i.e. $403 \mathrm{bp}$ ) and mismatches preventing the reads from being merged. Standardised trimming parameters were applied across all samples in order to minimise bias in merging the paired reads. Clustering at $97 \%$ identity across all samples, produced 727 OTUs (Additional file 2, Additional file 3: Table S4). Following chimera removal there were 324 OTUs across the entire dataset, including 44 OTUs in tenerals and 309 OTUs in mature adults, and sequences were reduced to $1,018,739(41.5 \%)$ ranging from 11 to 19,606 in tenerals and 7850 to 57,800 in mature adults.

The comparative number of $16 \mathrm{~S}$ rRNA gene sequence reads across libraries can be used as an indicator of the 
relative bacterial load across samples. The total sequence reads, or bacterial loads were higher in mature adults ( $x$ $=25,190.36 \pm 1674.84 \mathrm{SE})$ than in tenerals $(x=$ $1911.32 \pm 1076.351$ SE) $\left(F_{1,57}=85.15, p<0.001\right.$; Fig. 1 and Additional file 1 Table S2). The colony origin affected sequence reads in tenerals $\left(F_{1,12}=5.23, p<0.05\right)$ where FFPF tenerals $(x=1167.00 \pm 544.80 \mathrm{SE})$ had more reads than HIE tenerals $(x=22.14 \pm 4.01 \mathrm{SE})$. The irradiation of pupae also resulted in a higher count of sequence reads in mature adults $\left(F_{1,25}=4.89, p=<0.05\right)$ with irradiated matures $(x=31,403.08 \pm 3676.84$ SE) having more sequence reads than unirradiated matures $(x=22,367.69 \pm 1780.03 \mathrm{SE})$. The other parameters of sex and adult diet (for mature adults only), had no discernible impact on bacterial sequence read count (Additional file 1 Table S2).

\section{Alpha diversity}

Rarefaction curve (Fig. 2) and Good's coverage (Additional file 1 Table S1) indicated that microbial communities of the mature adults were well captured by the sequencing coverage. The reads from the mature fly samples were rarefied to 5500 and were represented by 309 observed OTUs. The most OTU diverse mature sample was one unirradiated female, kept on a full adult diet (containing yeast hydrolysate and sugar), originating from a FFPF pupa (ELYUF02) that contained 102 OTUs. The rest of the mature samples were much less diverse and contained between 12 and 44 OTUs. The sequences from the tenerals clustered into 44 OTUs following rarefaction to 10 sequences per sample (Fig. 3), but only nine out of 19 samples achieved adequate sequence coverage at this low value.

Colony origin significantly influenced the number of OTUs in both mature $\left(F_{1,25}=9.055, p<0.01\right)$ and teneral flies $\left(F_{1,12}=20.93, p<0.001\right)$ (Additional file 1 Table S3). Mature adult flies derived from FFPF pupae had more OTUs $(x=37.39 \pm 5.86 \mathrm{SE})$ than mature flies derived from HIE pupae $(x=19.39 \pm 1.18 \mathrm{SE})$. Contrary to the mature adults, HIE tenerals $(x=7.71 \pm 0.52 \mathrm{SE})$ were more OTU diverse than FFPF tenerals $(x=2.17 \pm 1.17$ $\mathrm{SE})$. Sex, irradiation, and adult diets were observed to not affect the number of OTUs in adult flies.

\section{Beta diversity}

Beta diversity measurements were applied to sequences clustered at $97 \%$ similarity using the weighted and unweighted UniFrac and Bray-Curtis distances (Fig. 4). In the tenerals, the PCoA of all three measurements indicated an emerging pattern of separation between samples based on colony origin. This pattern was also visible in mature flies. Further to this, the Bray-Curtis distance PCoA within the irradiated mature flies showed a separation between flies fed a full adult diet, and those fed an adult diet of sugar only. No sex effect was observed in the PCoAs.

\section{Identity of dominant bacterial OTUs}

For the entire dataset, the nine most abundant OTUs represented over $80 \%$ of the rarefied combined mature

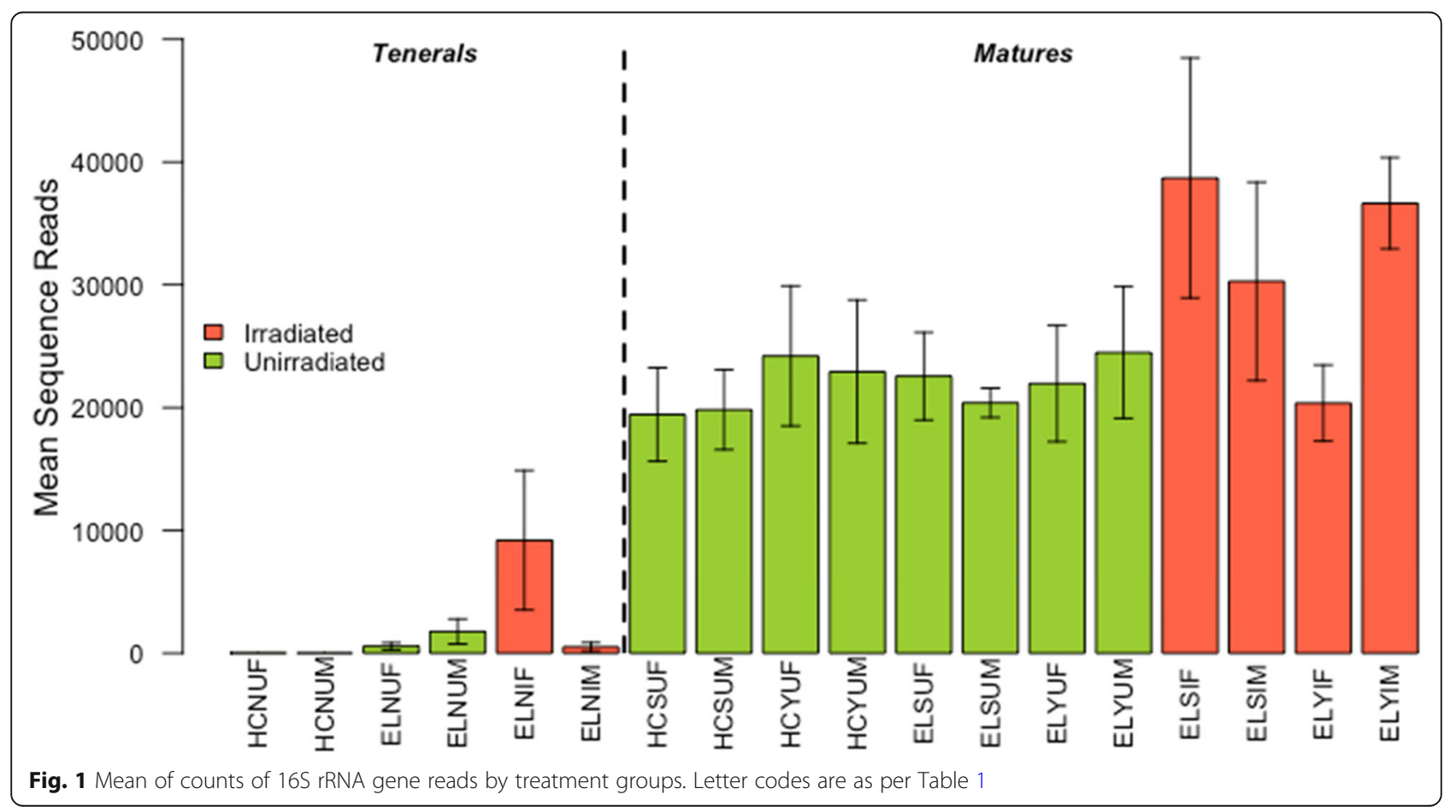




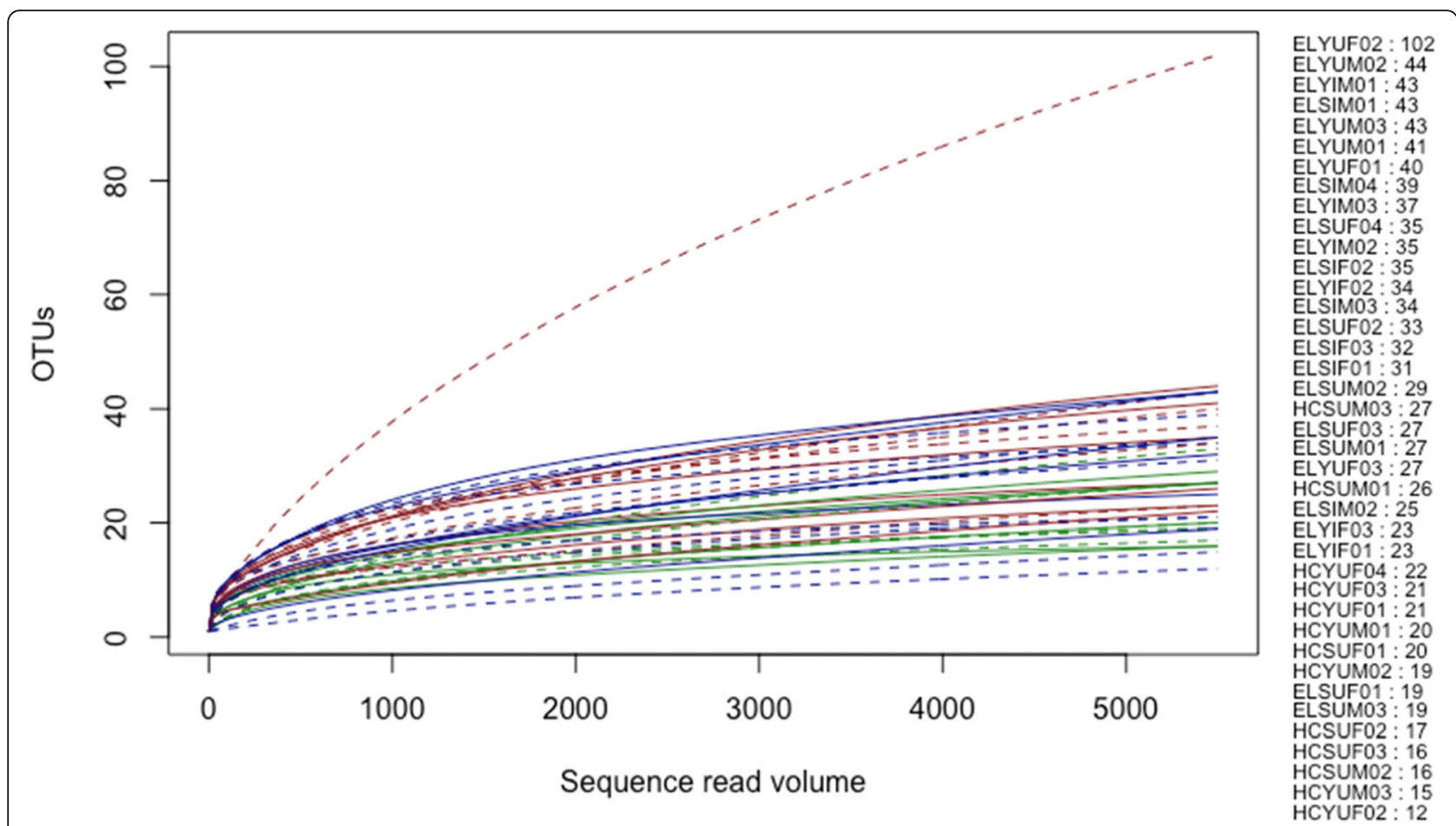

Fig. 2 Rarefaction curves for mature Bactrocera tryoni. Figures to the right of the graph indicate the order of lines as sorted by number of OTUs. Sample name letter codes are as per Table 1

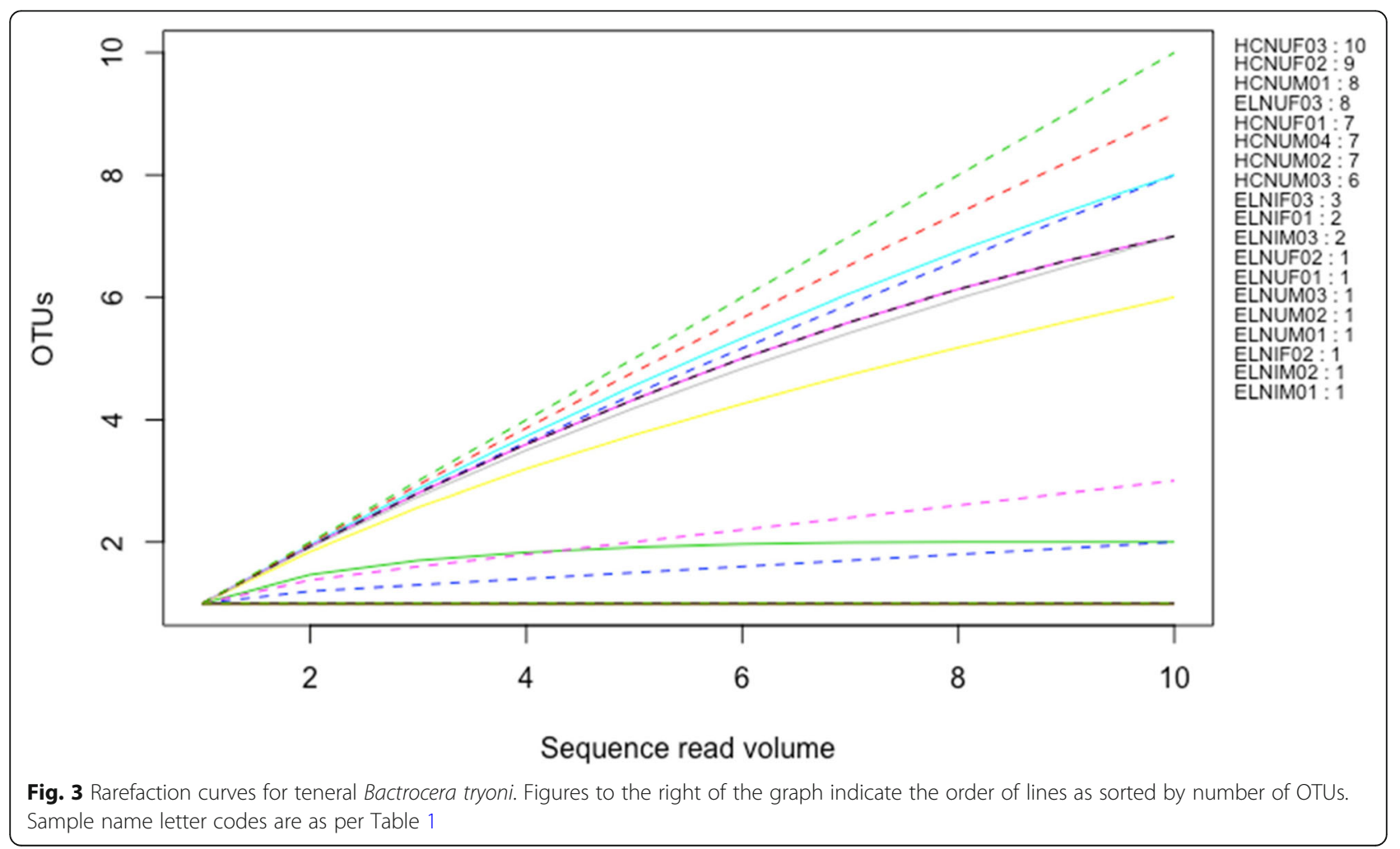




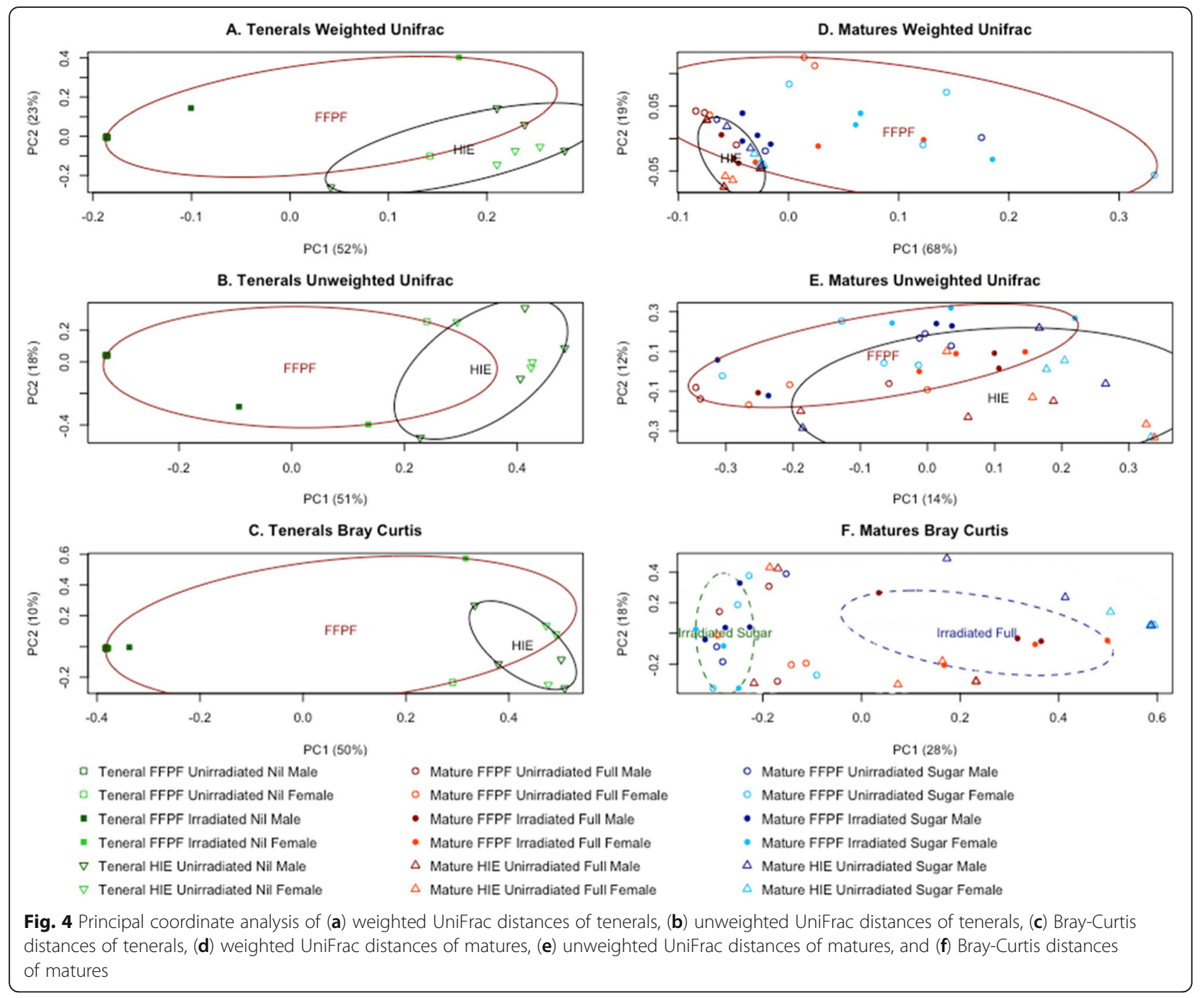

and teneral sequence reads (Table 2, Additional file 3). Based on the BLAST search of the short 16S rRNA gene amplicons, these dominant OTUs likely belonged to the Enterobacteriaceae genera Enterobacter (1 OTU), Pluralibacter/Klebsiella (2 OTUs), Proteus (1 OTU), Providencia (2 OTUs) and Serratia (2 OTUs), and to the Acetobacteraceae genus Asaia (1 OTU).

In mature flies, the most abundant and OTU diverse bacterial family was Enterobacteriaceae, comprising 116 OTUs (Fig. 5). The high abundance of Enterobacteriaceae in matures was mostly due to 8 OTUs that accounted for over $86 \%$ of the total rarefied mature adult sequence reads (Table 2). The second most abundant bacterial family in the mature flies was Acetobacteraceae, where one of the 11 OTUs accounted for $11 \%$ of the total rarefied mature adult sequence reads. Based on a BLAST search, this dominant Acetobacteraceae OTU belonged to the genus Asaia.

The HIE tenerals harboured 10 OTUs classified to Enterobacteriaceae, and were dominated by the same
Enterobacteriaceae OTUs that were highly abundant in the mature flies (Table 2). The FFPF tenerals contained two Acetobacteraceae OTUs, but were dominated by one OTU that accounted for $51 \%$ of the total rarefied teneral sequence reads (Fig. 6). The dominant Acetobacteraceae OTU in tenerals, as in matures, was Asaia. Other notable OTUs in tenerals included Planococcaceae (according to the short 16S rRNA gene amplicon possibly a Staphylococcus sp.), and mitochondrial $16 \mathrm{~S}$ rRNA gene from Poaceae (grasses), probably from the cane sugar used in the FFPF larval diet, and hits to a chloroplast 16S rRNA gene. Asaia or other Acetobacteraceae were not found in teneral and mature HIE flies.

The relative abundance plot (Fig. 7) suggested a pattern in mature FFPF flies (which were dominated by Acetobacteraceae in the teneral stage) that favoured, irrespective of irradiation, the proliferation of Enterobacteriaceae (and reduced relative presence of Acetobacteraceae) when fed the full adult diet over those fed the sugar only adult diet. 


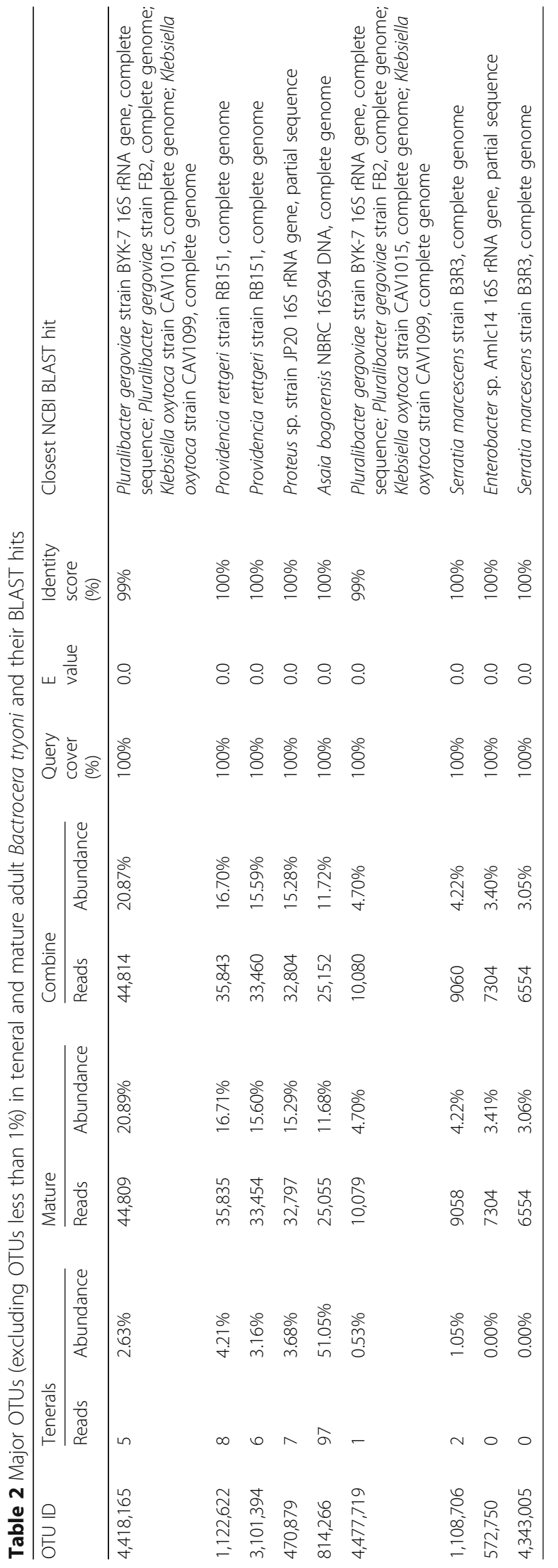




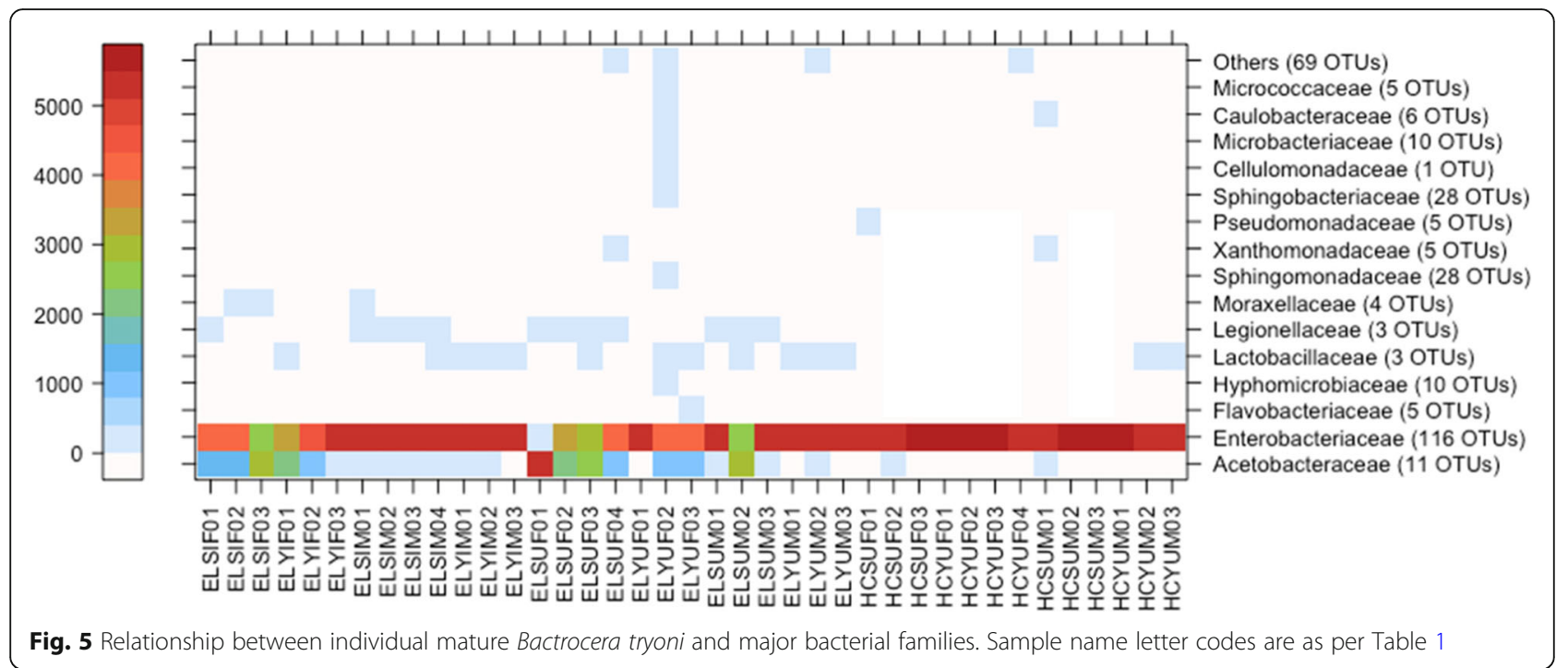

Furthermore, for FFPF matures, it appeared that females had higher relative abundance of Acetobacteraceae than males when fed sugar however this was not observed when FFPF flies were fed a full adult diet.

\section{Discussion}

We used 16S rRNA gene amplicon sequencing to characterise the bacterial community composition and structure of individual adult $B$. tryoni and to evaluate the impact of colony origin, adult diets and irradiation on the bacterial community across two adult developmental stages. Tenerals consistently had reduced total bacterial titres when compared with mature adult flies. This may be due to the bottleneck that bacterial populations experience as a consequence of the emptying of gut content prior to pupation during holometabolous metamorphosis. An overall low bacterial count in larvae, pupae and teneral flies was also observed for Mediterranean fruit fly, Ceratitis capitata

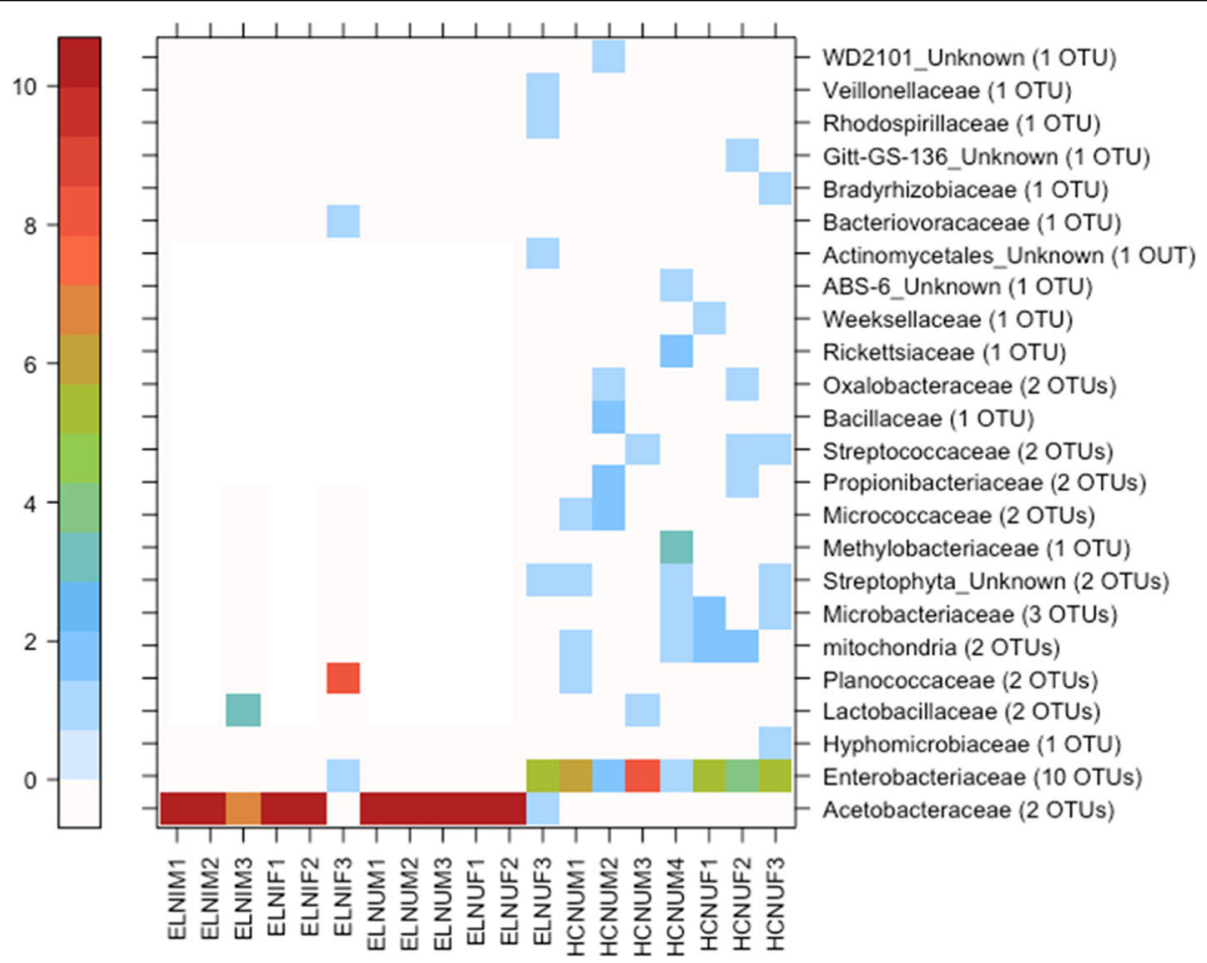

Fig. 6 Relationship between individual teneral Bactrocera tryoni and bacterial families. Sample name letter codes are as per Table 1 


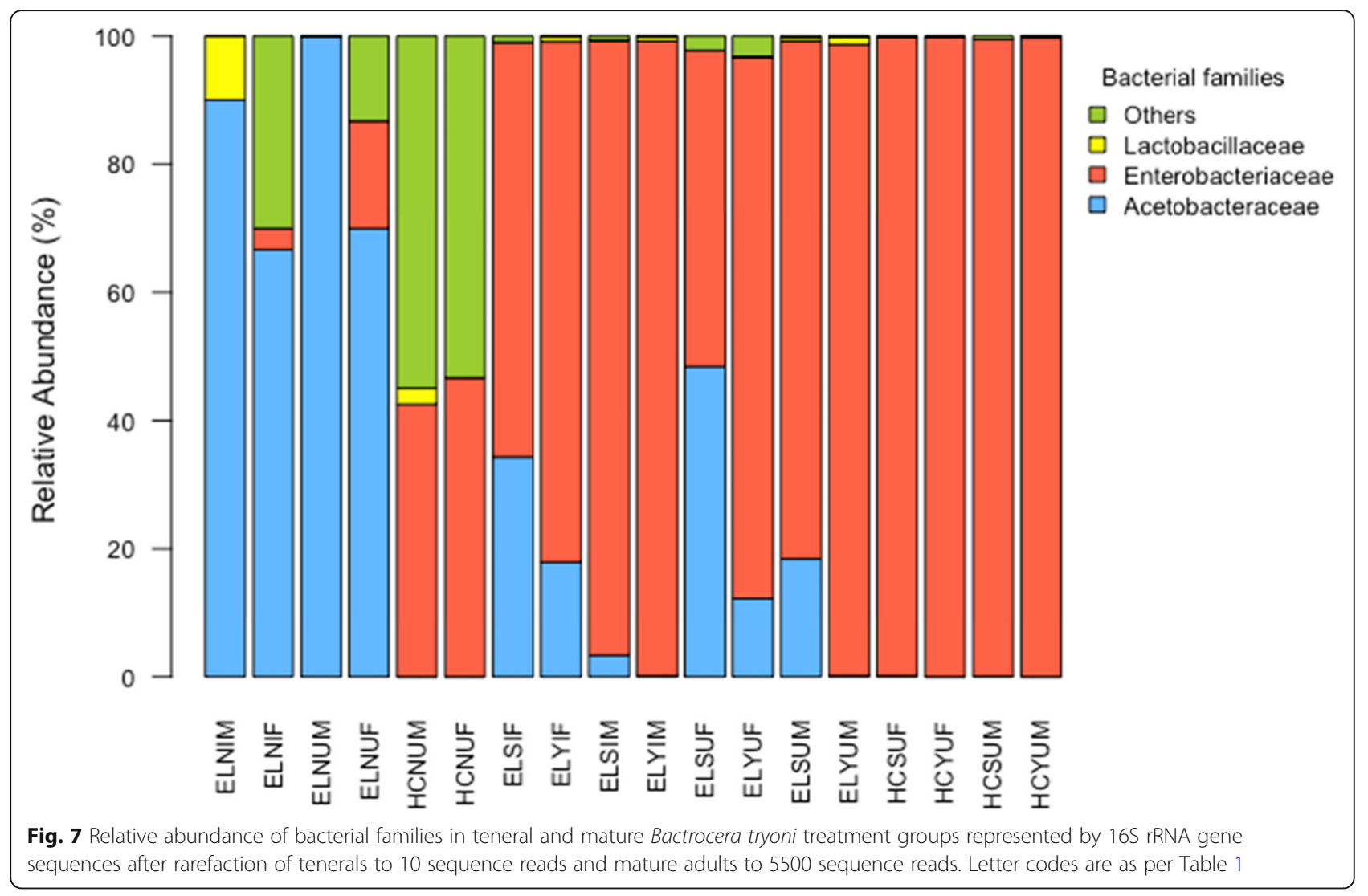

(Wiedemann), (Diptera: Tephritidae) [31]. Another possible explanation for the differences found between teneral and mature flies may be that larvae are less mobile and restricted to one diet while pupae are a non-feeding, largely sessile stage and, therefore, have reduced exposure to diverse microbial communities compared with adults. Due to their mobility, adult flies have the potential to forage from diverse food sources across environments with variable microbial communities (particularly in the field and to some extent when in a captive colony).

Unexpectedly, irradiated mature B. tryoni had a higher bacterial sequence read volume than unirradiated individuals, suggesting an increased bacterial load. Given that such irradiation effects on gut bacterial communities have not yet been investigated in other tephritids, our findings warrant further investigation of bacterial population dynamics in irradiated flies. Despite the damage caused by irradiation on a tephritid gut [13], previous research demonstrated that irradiated tephritids still display normal proteolytic activity [32]. Therefore, the damage caused by irradiation may enable some bacteria to exploit newly available resources, and/or compensate for the damage. Alternatively, we can also postulate that the damage caused by irradiation allows some bacteria to proliferate in the gut due to an inability of irradiated fruit flies to regulate their bacterial load. However, this increased bacterial load did not impact the total bacterial diversity and relative abundance of OTUs.

Although the effects of adult diets on tephritids have been well characterised [33-35], to date little is known about the impact of diets on their microbiome [36]. The comparison of OTU diversity between teneral and mature adults revealed a clear distinction between flies with different colony origins (at FFPF and HIE, flies were reared on different larval diets in different environments and were sourced from different field populations in different years). This is consistent with the PCoA plots (Fig. 4 a, b, c, d, and e) where an emerging separation was visible between samples from different colony origins.

The colony origin significantly influenced the number of sequence reads in tenerals and the number of OTUs in both tenerals and matures. The flies from the FFPF and HIE were derived from different lines. Further, the FFPF line had been captive for under 2 years, while the HIE colony had been established for 6 years. Fruit flies are known to lose their field characteristics in as little as three generations $[5,37]$ as they become domesticated. Further to this, FFPF flies were reared at higher densities compared to the HIE flies and this may have impacted the stress of the environment for developing larvae, and prior generations of adult flies. Therefore, different host 
genotypes and environmental influences such as larval densities could play a part in the different bacterial community composition observed between flies originating from the FFPF and HIE. Although we cannot entirely separate the effects of larval diet, larval environment (including density of larvae in the diet) and domestication history of the two fly colonies, it remains likely that the different bulking agents used in the larval diets of FFPF and HIE were probably important contributors to the observed differences in the bacterial community in tenerals. Regardless of the pupal origin, as the adult flies matured within the same environment, the bacterial communities became increasingly similar; therefore, the adult environment impacted the bacterial communities of flies as they developed.

Besides this effect of colony origin, our study of captive $B$. tryoni indicates that, within diet treatments, the bacterial communities were similar in composition between male and female flies. Therefore, we can exclude any sex effects on bacterial community composition in captive flies.

Based on the short 16S rRNA gene amplicons, the genera of the dominant OTUs in the reared populations for $B$. tryoni were Enterobacter, Pluralibacter/Klebsiella, Proteus, Providencia and Serratia (Enterobacteriaceae) and Asaia (Acetobacteraceae). The dominance by Enterobacteriaceae supports previous findings from microbiome studies of $B$. tryoni $[11,38]$, and other tephritids of the Bactrocera genus including B. cacuminata [11, 38], B. carambolae [39], B. cucurbitae [40, 41], B. dorsalis [39, 42-45], B. jarvisi [11], B. neohumeralis [11], B. minax [46], B. oleae [47, 48], B. tau [49-51] and B. zonata [52].

Teneral B. tryoni originating from FFPF pupae were dominated by Acetobacteraceae (mostly Asaia) but, in the mature stage, these flies had a lower proportional representation of this bacterial family than Enterobacteriaceae, and provision of a full adult diet exacerbated this effect. This may suggest that the ratio of carbohydrates and proteins in the adult diet may shift bacterial community structure. Nitrogen, the key element in proteins, is considered to be a limiting factor in the reproductive success of both male and female C. capitata [53, 54]. Despite the provision of yeast as a protein source, nitrogen is paradoxically limited [55]. Enterobacteriaceae are known to contain diazotrophic species [56] which would assist in providing more or specifically required forms of nitrogen. This would explain the abundance of Enterobacteriaceae in mature adult B. tryoni. Enterobacteriaceae species have also been credited for improving egg production in female B. oleae $[15,47]$ and improved mating performance in male C. capitata $[12,57]$. These studies have sparked the research interest into the use of Enterobacteriaceae candidates to enhance performance of B. tryoni $[58,59]$.
The high abundance of Asaia in B. tryoni adult flies reared from FFPF pupae (but not seen in adult HIE flies) is a novel finding as previous studies found Asaia only at low abundance in adult B. tryoni [11] and B. oleae [60]. Furthermore, Asaia has recently been detected at high abundance in B. tryoni larvae obtained from field collected fruit, and in larvae reared in artificial diets [61]. The role of Asaia sp. in tephritids is still unknown, however, bacteria of this genus are dominant taxa in the microbiota of larvae and several adult mosquitoes (Anopheles gambiae, A. maculipennis and A. stephensi) $[62,63]$. Asaia spp. have been found to be important in the development of $A$. stephensi as when deprived of it, larval development was delayed [64].

\section{Conclusion}

Our study has shown that the microbiome of B. tryoni during adult development is impacted by irradiation, the environment and the adult diet, with a very similar microbiome shared between male and female captive and domesticated B. tryoni. Symbiotic bacteria have previously been supplemented to larval and adult diets of other tephritid pest species with the aim to improve the performance of mass-reared flies in SIT programmes [2]. Our findings demonstrate that colony origin (in our study, compounded by differences in larval diets, rearing environments, field source populations and duration of domestication) and adult diets impact mature B. tryoni gut microbiota. However, diet composition (such as the ratio of carbohydrates and protein) is evidently an important factor for the application of fruit fly probiotics. Importantly, our work also suggests that the ideal time to introduce a probiotic to impact the mature adult tephritids' microbiota is from the teneral stage, which is consistent with the 2 to 3 day pre-release holding period for sterile adult B. tryoni during which the adults are provided with food and water [65]. The dominance of the bacterial families Enterobacteriaceae and Acetobacteraceae, specifically Asaia sp., warrants more research into the association of these bacteria with $B$. tryoni, particularly in understanding the role they currently play in mass-rearing and performance of the sterile individuals released in SIT programmes.

\section{Supplementary information}

Supplementary information accompanies this paper at https://doi.org/10. 1186/s12866-019-1649-6.

Additional file 1: Table S1. Alpha diversity metrics of 58 gut samples from Bactrocera tryoni reared on artificial diets, calculated at $97 \%$ identity level, after rarefaction of tenerals to 10 sequence reads and matures to 5500 sequence reads. Table S2. ANOVA of $16 \mathrm{~S}$ rRNA gene sequence reads of teneral and mature adult Bactrocera tryoni. Table S3. ANOVA of number of OTUs in Bactrocera tryoni. 
Additional file 2. Representative set of $16 \mathrm{~S}$ rRNA gene sequences of OTUs from teneral and mature Bactrocera tryoni.

Additional file 3: Table S4. OTU Table.

\section{Abbreviations}

ANSTO: Australian Nuclear Science and Technology Organisation; CCPIC: Central Coast Primary Industries Centre; DPI: Department of Primary Industries; FFPF: Fruit Fly Production Facility; HIE: Hawkesbury Institute for the Environment; NSW: New South Wales; NGS: Next Generation Sequencing; OTU: Operational Taxonomic Unit; PCoA: Principal Component Analysis: SIT: Sterile Insect Technique

\section{Acknowledgements}

We are grateful to Duong Nguyen at HIE and Solomon Balagawi at FFPF (NSW DPI - EMAI) who provided the Queensland fruit fly pupae and also to Emma Hackett and Caroline Janitz at the Western Sydney University NGS facility for NGS library preparations and processing sample runs. We also thank Lucas Shuttleworth and Leigh Pilkington for comments on a draft manuscript, and anonymous reviewers for additional constructive edits and comments during the review process.

\section{About this supplement}

This article has been published as part of BMC Microbiology Volume 19 Supplement 1, 2019: Proceedings of an FAO/IAEA Coordinated Research Project on Use of Symbiotic Bacteria to Reduce Mass-rearing Costs and Increase Mating Success in Selected Fruit Pests in Support of SIT Application: microbiology. The full contents of the supplement are available online at https://bmcmicrobiol. biomedcentral.com/articles/supplements/volume-19-supplement-1.

\section{Authors' contributions}

This experiment was conceptualised by DNW, JLM and MR and developed together with OLR and TAC. Data were collected by DNW under the supervision of JLM, OLR, TAC and MR. Data were analysed by DNW, JLM and DPC. Data were interpreted by DNW, JLM, OLR, TAC and MR. The manuscript was drafted by DNW with the input of all authors. All authors have approved submission of the article.

\section{Funding}

This research was supported by the Australian Government's Cooperative Research Centre Programme through the Plant Biosecurity Cooperative Research Centre (PBCRC), the Australian Government's ARC Industrial Transformation Training Centre Fruit Fly Biosecurity Innovation, NSW DPI, Western Sydney University and HIE.

\section{Availability of data and materials}

The datasets generated and/or analysed during the current study are available as attachment in the Additional files and also in the NCBI SRA repository, BioProject ID: PRJNA579218.

\section{Ethics approval and consent to participate}

Not applicable.

\section{Consent for publication}

Not applicable.

\section{Competing interests}

The authors declare that they have no competing interests.

\section{Author details}

${ }^{1}$ Plant Biosecurity Cooperative Research Centre, LPO, Box 5012, Bruce, ACT 2617, Australia. ${ }^{2}$ Hawkesbury Institute for the Environment, Western Sydney University, Locked Bag 1797, Penrith, NSW 2751, Australia. ${ }^{3}$ Biosecurity and Food Safety, NSW Department of Primary Industries, Elizabeth Macarthur Agricultural Institute, Private Bag 4008, Narellan, NSW 2567, Australia. ${ }^{4}$ Graham Centre for Agricultural Innovation (an alliance between Charles Sturt University and NSW DPI), Locked Bag 588, Wagga Wagga, NSW 2678, Australia. ${ }^{5}$ cesar Pty Ltd, 293 Royal Parade, Parkville, Victoria 3052, Australia. ${ }^{6}$ Biometrics Unit, NSW Department of Primary Industries, Elizabeth Macarthur Agricultural Institute, Private Bag 4008, Narellan, NSW 2567, Australia.

\section{Published: 24 December 2019}

\section{References}

1. Petri L. Untersuchung ueber die Darmbakterien der Olivenfliege. Zentbl Bakteriolog. 1910:26:357-67.

2. Yuval B, Ben-Ami E, Behar A, Ben-Yosef M, Jurkevitch E. The Mediterranean fruit fly and its bacteria-potential for improving sterile insect technique operations. J Appl Entomol. 2013;137(s1):39-42.

3. Lauzon C. Symbiotic relationships of tephritids. In: Bourtzis K, Miller T, editors. Insect Symbiosis, vol. 1. Boca Raton: CRC Press; 2003. p. 115-30.

4. Yuval B, Ben Ami E, Behar A, Ben-Yosef M, Jurkevitch E. The Mediterranean fruit fly and its bacteria-potential for improving sterile insect technique operations. J Appl Entomol. 2010;137(s1):39-42.

5. Gilchrist A, Cameron E, Sved J, Meats A. Genetic consequences of domestication and mass rearing of pest fruit fly Bactrocera tryoni (Diptera: Tephritidae). J Econ Entomol. 2012;105(3):1051-6.

6. Knipling E. Possibilities of insect control or eradication through the use of sexually sterile males. J Econ Entomol. 1955:48(4):459-62.

7. Collins S, Weldon C, Banos C, Taylor P. Effects of irradiation dose rate on quality and sterility of Queensland fruit flies, Bactrocera tryoni (Froggatt). J Appl Entomol. 2008;132(5):398-405

8. Taylor P, Pérez-Staples D, Weldon C, Collins S, Fanson B, Yap S, Smallridge C. Post-teneral nutrition as an influence on reproductive development, sexual performance and longevity of Queensland fruit flies. J Appl Entomol. 2013; 137(s1):113-25.

9. Yuval B, Kaspi R, Field S, Blay S, Taylor P. Effects of post-teneral nutrition on reproductive success of male Mediterranean fruit flies (Diptera: Tephritidae). Fla Entomol. 2002;85(1):165-70.

10. Yuval B, Maor M, Levy K, Kaspi R, Taylor P, Shelly T. Breakfast of champions or kiss of death? Survival and sexual performance of protein-fed, sterile Mediterranean fruit flies (Diptera: Tephritidae). Fla Entomol. 2007;90(1):115-22

11. Morrow J, Frommer M, Shearman D, Riegler M. The microbiome of fieldcaught and laboratory-adapted Australian tephritid fruit fly species with different host plant use and specialisation. Microb Ecol. 2015;70(2):498-508.

12. Niyazi N, Lauzon C, Shelly T. Effect of probiotic adult diets on fitness components of sterile male Mediterranean fruit flies (Diptera: Tephritidae) under laboratory and field cage conditions. J Econ Entomol. 2004;97(5): 1570-80.

13. Lauzon C, Potter S. Description of the irradiated and nonirradiated midgut of Ceratitis capitata Wiedemann (Diptera: Tephritidae) and Anastrepha ludens Loew (Diptera: Tephritidae) used for sterile insect technique. J Pest Sci. 2012;85(2):217-26.

14. Hamden H, Guerfali MM, Fadhl S, Saidi M, Chevrier C. Fitness improvement of mass-reared sterile males of Ceratitis capitata (Vienna 8 strain) (Diptera: Tephritidae) after gut enrichment with probiotics. J Econ Entomol. 2013; 106(2):641-7.

15. Sacchetti P, Ghiardi B, Granchietti A, Stefanini F, Belcari A. Development of probiotic diets for the olive fly: evaluation of their effects on fly longevity and fecundity. Ann Appl Biol. 2014;164(1):138-50.

16. Jessup A, Dominiak B, Woods B, De Lima C, Tomkins A, Smallridge C. Areawide management of fruit flies in Australia. In: Vreysen M, Robinson A Hendrichs J, editors. Area-Wide Control of Insect Pests. Dordrecht: Springer; 2007. p. 685-97.

17. Dominiak B, Westcott A, Barchia I. Release of sterile Queensland fruit fly, Bactrocera tryoni (Froggatt) (Diptera: Tephritidae), at Sydney, Australia. Aus J Exp Agric. 2003;43(5):519-28

18. Fanson B, Sundaralingam $S$, Jiang $L$, Dominiak B, D'Arcy G. A review of 16 years of quality control parameters at a mass-rearing facility producing Queensland fruit fly, Bactrocera tryoni. Entomologia Exp Applicata. 2014; 151(2):152-9.

19. Meats A, Holmes H, Kelly G. Laboratory adaptation of Bactrocera tryoni (Diptera: Tephritidae) decreases mating age and increases protein consumption and number of eggs produced per milligram of protein. Bull Entomol Res. 2004;94(06):517-24.

20. Perez-Staples D, Prabhu V, Taylor P. Post-teneral protein feeding enhances sexual performance of Queensland fruit flies. Physiol Entomol. 2007;32(3):225-32

21. Reynolds O, Dominiak B, Orchard B. Pupal release of the Queensland fruit fly, Bactrocera tryoni (Froggatt)(Diptera: Tephritidae), in the sterile insect 
technique: seasonal variation in eclosion and flight. Aust J Entomol. 2010; 49(2):150-9.

22. Morrow J, Hall A, Riegler M. Symbionts in waiting: the dynamics of incipient endosymbiont complementation and replacement in minimal bacterial communities of psyllids. Microbiome. 2017;5(1):58.

23. Caporaso J, Kuczynski J, Stombaugh J, Bittinger K, Bushman F, Costello E, Fierer N, Peña A, Goodrich J, Gordon J, et al. QIIME allows analysis of highthroughput community sequencing data. Nat Methods. 2010;7(5):335-6.

24. FastQC: a quality control tool for high throughput sequence data [http:// www.bioinformatics.babraham.ac.uk/projects/fastqc]. Accessed 5 Nov 2018

25. Shen W, Le S, Li Y, Hu F. SegKit: A Cross-Platform and Ultrafast Toolkit for FASTA/Q File Manipulation. PLoS ONE. 2016;11(10):e0163962.

26. Magoč T, Salzberg S. FLASH: fast length adjustment of short reads to improve genome assemblies. Bioinformatics. 2011;27(21):2957-63.

27. Haas B, Gevers D, Earl A, Feldgarden M, Ward D, Giannoukos G, Ciulla D, Tabbaa D, Highlander S, Sodergren E. Chimeric 165 rRNA sequence formation and detection in sanger and 454-pyrosequenced PCR amplicons. Genome Res. 2011;21(3):494-504.

28. R Development Core Team. R: A language and environment for statistical computing. In: 3.4.0 (2017-04-21) — "You Stupid Darkness". Vienna: R Foundation for Statistical Computing; 2017.

29. Oksanen J, Blanchet F, Friendly M, Kindt R, Legendre P, McGlinn D, Minchin P, O'Hara R, Simpson G, Solymos P, et al. Vegan: Community Ecology Package. In: R package version 2.4-3; 2017.

30. Sarkar D. Lattice: multivariate data visualization with R. New York: Springer; 2008.

31. Aharon Y, Pasternak Z, Ben-Yosef M, Behar A, Lauzon C, Yuval B, Jurkevitch E Phylogenetic, metabolic, and taxonomic diversities shape Mediterranean fruit fly microbiotas during ontogeny. Appl Environ Microbiol. 2013;79(1):303-13.

32. San Andres V, Ortego F, Castañera P. Effects of gamma-irradiation on midgut proteolytic activity of the mediterranean fruit fly, Ceratitis capitata (Diptera: Tephritidae). Arch Insect Biochem Physiol. 2007;65(1):11-9.

33. Fanson B, Weldon C, Pérez-Staples D, Simpson S, Taylor P. Nutrients, not caloric restriction, extend lifespan in Queensland fruit flies (Bactrocera tryoni). Aging Cell. 2009;8(5):514-23.

34. Reynolds O, Orchard B, Collins S, Taylor P. Yeast hydrolysate supplementation increases field abundance and persistence of sexually mature sterile Queensland fruit fly, Bactrocera tryoni (Froggatt). Bull Entomol Res. 2014;104(02):251-61.

35. Kaspi R, Yuval B. Post-teneral protein feeding improves sexual competitiveness but reduces longevity of mass-reared sterile male Mediterranean fruit flies (Diptera: Tephritidae). Ann Entomol Soc Am. 2000;93(4):949-55.

36. Wang $\mathrm{H}$, Jin $\mathrm{L}$, Zhang $\mathrm{H}$. Comparison of the diversity of the bacterial communities in the intestinal tract of adult Bactrocera dorsalis from three different populations. J Appl Microbiol. 2011;110(6):1390-401.

37. Hoffmann A, Hallas R, Sinclair C, Partridge L. Rapid loss of stress resistance in Drosophila melangaster under adaptation to laboratory culture. Evolution. 2001;55(2):436-8.

38. Thaochan N, Drew R, Hughes J, Vijaysegaran S, Chinajariyawong A. Alimentary tract bacteria isolated and identified with API-20E and molecular cloning techniques from Australian tropical fruit flies, Bactrocera cacuminata and B tryoni. J Insect Sci. 2009;10:131.

39. Yong H, Song S, Chua K, Lim P. Microbiota associated with Bactrocera carambolae and B. dorsalis (Insecta: Tephritidae) revealed by next-generation sequencing of 16S rRNA gene. Meta Gene. 2017;11:189-96

40. Thaochan N, Chinajariyawong A, Drew R. Classical and molecular study of gut bacterial community structure in alimentary tract of Bactrocera cucurbitae (Coquillett). In: Munoz B, Llopis V, Garcia A, editors. 8th International Symposoium on Fruit Flies of Economic Importance. Valencia: Editorial Universitat Politecnica de Valencia; 2010. p. 37-55.

41. Hadapad A, Prabhakar C, Chandekar S, Tripathi J, Hire R. Diversity of bacterial communities in the midgut of Bactrocera cucurbitae (Diptera: Tephritidae) populations and their potential use as attractants. Pest Manag Sci. 2016; 72(6):1222-30.

42. Andongma A, Wan L, Dong Y, Li P, Desneux N, White J, Niu C. Pyrosequencing reveals a shift in symbiotic bacteria populations across life stages of Bactrocera dorsalis. Sci Rep. 2015;5:9470.

43. Wang $H$, Jin $L$, Peng $T$, Zhang $H$, Chen Q, Hua Y. Identification of cultivable bacteria in the intestinal tract of Bactrocera dorsalis from three different populations and determination of their attractive potential. Pest Manag Sci. 2014;70(1):80-7.
44. Thaochan N, Sittichaya W, Sausa-ard W, Chinajariyawong A. Incidence of Enterobacteriaceae in the larvae of the polyphagous insect (Bactrocera papayae) Drew \& Hancock (Diptera: Tephritidae) infesting different host fruits. Philipp Agric Scientist. 2013;96(4):384-91.

45. Pramanik M, Khan M, Miah A. Isolation and identification of mid-gut bacterial community of Bactrocera dorsalis (Hendel)(Diptera: Tephritidae). Res J Microbiol. 2014;9(6):278.

46. Wang $A$, Yao Z, Zheng $W$, Zhang $H$. Bacterial communities in the gut and reproductive organs of Bactrocera minax (Diptera: Tephritidae) based on 454 pyrosequencing. PLoS One. 2014;9(9):e106988.

47. Ben-Yosef $M$, Aharon $Y$, Jurkevitch $E$, Yuval B. Give us the tools and we will do the job: symbiotic bacteria affect olive fly fitness in a diet-dependent fashion. Proc Royal Soc - Biol Sci. 2010;277(1687):1545-52.

48. Kounatidis I, Crotti E, Sapountzis P, Sacchi L, Rizzi A, Chouaia B, Bandi C, Alma A, Daffonchio D, Mavragani-Tsipidou P, et al. Acetobacter tropicalis is a major symbiont of the olive fruit fly (Bactrocera oleae). Appl Environ Microbiol. 2009;75(10):3281-8.

49. Sood P, Nath A. Colonization of marker strains of bacteria in fruit fly, Bactrocera tau. Indian J Agric Res. 2005;39(2):103.

50. Prabhakar C, Sood P, Kanwar S, Sharma P, Kumar A, Mehta P. Isolation and characterization of gut bacteria of fruit fly, Bactrocera tau (Walker). Phytoparasitica. 2013;41(2):193-201.

51. Khan M, Mahin A, Pramanik M, Akter H. Identification of gut bacterial community and their effect on the fecundity of pumpkin fly, Bactrocera tau (Walker). J Entomol. 2014;11(2):68-77.

52. Reddy K, Sharma K, Singh S. Attractancy potential of culturable bacteria from the gut of peach fruit fly, Bactrocera zonata (Saunders). Phytoparasitica. 2014:42(5):691-8.

53. Yuval B, Hendrichs J. Behavior of fies in the genus Ceratitis (Dacinae: Ceratitidini). In: Fruit flies (Tephritidae): phylogeny and evolution of behavior. Boca Raton: CRC; 2000. p. 429-57.

54. Yuval B, Kaspi R, Shloush S, Warburg M. Nutritional reserves regulate male participation in Mediterranean fruit fly leks. Ecol Entomol. 1998;23(2):211-5.

55. Galloway J, Dentener F, Capone D, Boyer E, Howarth R, Seitzinger S, Asner G, Cleveland C, Green P, Holland E. Nitrogen cycles: past, present, and future. Biogeochemistry. 2004;70(2):153-226.

56. Behar A, Yuval B, Jurkevitch E. Enterobacteria-mediated nitrogen fixation in natural populations of the fruit fly Ceratitis capitata. Mol Ecol. 2005;14(9):2637-43.

57. Ben-Yosef $M$, Jurkevitch E, Yuval B. Effect of bacteria on nutritional status and reproductive success of the Mediterranean fruit fly Ceratitis capitata. Physiol Entomol. 2008:33(2):145-54.

58. Fitt G, O'Brien R. Bacteria associated with four species of Dacus (Diptera: Tephritidae) and their role in the nutrition of the larvae. Oecologia. 1985; 67(3):447-54.

59. Meats A, Streamer K, Gilchrist A. Bacteria as food had no effect on fecundity during domestication of the fruit fly, Bactrocera tryoni. J Appl Entomol. 2009; 133(8):633-9.

60. Sacchetti P, Granchietti A, Landini S, Viti C, Giovannetti L, Belcari A. Relationships between the olive fly and bacteria. J Appl Entomol. 2008; 132(9-10):682-9.

61. Deutscher A, Burke C, Darling A, Riegler M, Reynolds O, Chapman T. Near full-length 165 rRNA gene next-generation sequencing revealed Asaia as a common midgut bacterium of wild and domesticated Queensland fruit fly larvae. Microbiome. 2018;6:85.

62. Damiani C, Ricci I, Crotti E, Rossi P, Rizzi A, Scuppa P, Capone A, Ulissi U, Epis $\mathrm{S}$, Genchi M, et al. Mosquito-Bacteria Symbiosis: the case of Anopheles gambiae and Asaia. Microb Ecol. 2010;60(3):644-54.

63. Favia G, Ricci I, Damiani C, Raddadi N, Crotti E, Marzorati M, Rizzi A, Urso R, Brusetti L, Borin S, et al. Bacteria of the genus Asaia stably associate with Anopheles stephensi, an Asian malarial mosquito vector. Proc Natl Acad Sci. 2007:104(21):9047-51.

64. Chouaia B, Rossi P, Epis S, Mosca M, Ricci I, Damiani C, Ulissi U, Crotti E, Daffonchio D, Bandi C, et al. Delayed larval development in Anopheles mosquitoes deprived of Asaia bacterial symbionts. BMC Microbiol. 2012;12(1):S2.

65. Reynolds O, Smallridge C, Cockington V, Penrose L. Field release of adult sterile Queensland fruit fly, Bactrocera tryoni (Froggatt): the effect of release method and location on trap recapture rates. Aust J Entomol. 2012;51:116-26.

\section{Publisher's Note}

Springer Nature remains neutral with regard to jurisdictional claims in published maps and institutional affiliations. 